\title{
Doctor Fernando Cervigón Marcos: historia de una vida dedicada a la ictiología y al humanismo en latinoamericana 1930-2017
}

Nació el doctor Fernando Cervigón Marcos en Valencia (España) el 15 de mayo de 1930. Hizo sus estudios de secundaria en el Colegio de los Hermanos Maristas (1940-1948). Desarrollo sus estudios universitarios en la Universidad de Barcelona (1948-1955) en donde se graduó como Licenciado en Ciencias Naturales en 1955. Realizó sus cursos de posgrado (1957-1959) y sus estudios de doctorado (1964) en la Universidad de Barcelona, obteniendo el título de Doctor en Ciencias Biológicas, con la tesis "Los peces marinos de Venezuela", que fue publicada y calificada como Sobresaliente Cum Laude.

Descubrió y describió numerosas especies de peces. Fue autor de varias obras sobre los peces y el medio ambiente costero y oceánico de Venezuela incluyendo Los peces marinos de Venezuela en 1966, Volúmenes I y II. A este primer esfuerzo adicionó sucesivamente los complementos I (1968), II (1971), III (1973), IV (1975), V (1982), VI (1986) y, finalmente los libros síntesis I (1991), II (1993), III (1994), IV (1996), V (1999), y VI (2011).

Fundador y presidente del Museo del Mar, de la isla de Margarita, Nueva Esparta, Venezuela. También fue fundador de la Universidad Monteávila de

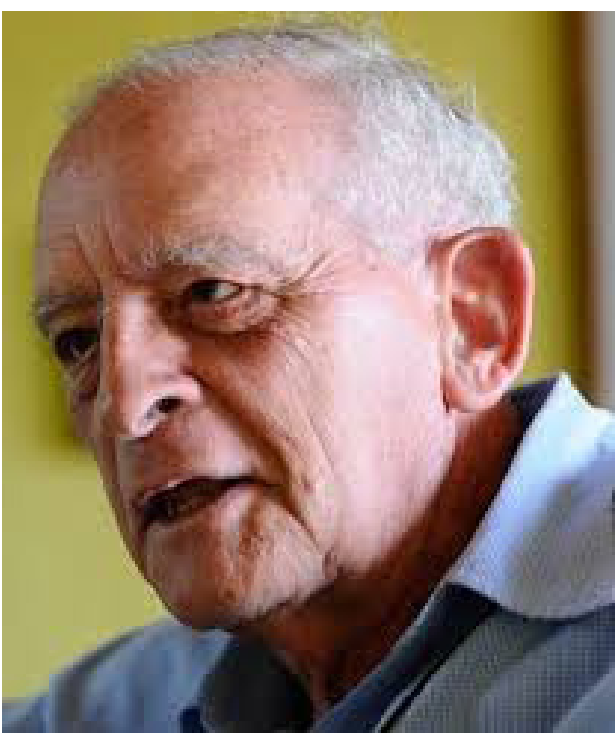
Caracas, en donde se desempeñó como Vicerrector Académico, profesor, conferencista y donde publicó diversas obras de carácter humanístico. El doctor Cervigón tuvo una dilatada y profunda obra en el conocimiento de la fauna marina venezolana, llegando a ser catalogado como el Padre de la Ictiología Marina en Venezuela.

Recibió numerosos reconocimientos y distinciones entre las que cabe destacar el Premio Nacional de Ciencias en 1988. En 2002, fue electo individuo de número de la Academia de Ciencias Físicas, Matemáticas y Naturales de Venezuela. En 1988, la Orden Andrés Bello en Primera Clase, en 1994 la Orden del Libertador grado "Gran Oficial”. Hijo adoptivo de los Municipios de la Península de Macanao y Tubores del Estado Nueva Esparta y declarado hijo ilustre del mismo estado por la Asamblea Regional en 2003.

Fue docente de la Universidad de Oriente y del Instituto Oceanográfico, investigador de la Fundación La Salle de Ciencias Naturales, investigador y miembro de la directiva de la Fundación Los Roques y fundador, director del Museo Marino de Margarita.

Con raíces españolas, a su querida isla Margarita le dedicó su vida desde 1960, cuando llegó a la península de Macanao, lugar que honró con sus conocimientos en el estudio de los peces. Lo han descrito como un hombre de mar, humanista y poseedor de un gran liderazgo, cualidades que le permitió amalgamarse a la gente para que cumplieran con entusiasmo y mística sus ideales.

Director científico de la Estación de Investigaciones Marinas de Margarita de la Fundación La Salle (1961-1970) y posteriormente como Profesor-Investigador de la Universidad de Oriente (1970-1980) donde ocupó el cargo de director de Instituto Oceanográfico en Cumaná (1973-74) y del Centro de Investigaciones Científicas del Núcleo de Nueva Esparta hasta 1980, jubilándose como profesor titular en 1990.

Fue comisionado por la oficina regional de UNESCO para dictar cursos y conferencias en varios países de Iberoamérica y Consultor de FAO en 1977-78 y 1991. Visitó en varias ocasiones entre 1970 y 1995, a Chile y especialmente a Colombia (Facultad de Biología Marina de la Universidad de Bogotá "Jorge Tadeo Lozano", en el Centro de Investigaciones Oceanográficas e Hidrográficas de la Escuela Naval "Almirante Padilla" y en el Instituto de Investigaciones Marinas y Costeras "José Benito Vives de Andréis”). En donde, además de sus cursos de ictiología, dirigió varias tesis profesiones y de posgrado. 
Además de sus trabajos científicos publicó numerosas obras relacionadas con aspectos de la naturaleza, la idiosincrasia humana de los isleños y se interesó por la historia regional y su proyección nacional. Entre estos temas merecen destacarse Gentes de Cubagua 1961, la Carpintería de Ribera en la Isla de Margarita (1988), Guía de campo de las especies comerciales (1990), Dependencias federales de Venezuela (1992), Araya: naturaleza y cultura (1995), Cubagua 500 años (1997), Las perlas en la historia de Venezuela (1998). La actividad pesquera en el estado de Nueva Esparta (2005), Paraguachoa (2008), Macanao (2010), Las raíces de la identidad hispanoamericana (2010), Islas de Venezuela, Venezuela submarina, Fernando Cervigón Marcos (textos) y Roger Laughlin (fotos) (2013)

Después de una prolongada temporada de delicada salud, falleció en Caracas el pasado 15 de mayo de 2017.

Algunas de sus publicaciones se mencionan en la información suplementaria que puede ver en el siguiente enlace: https:// www.raccefyn.co/index.php/raccefyn/article/downloadSuppFile/531/2214

\section{Ricardo Álvarez-León}

Fundación Verdes Horizontes. Manizales, Caldas.

ricardoalvarezleon@gmail.com 